\title{
Measles Outbreak among Roma People in Wrockaw, Poland, 2012
}

\author{
AGATA MAKÓWKA ${ }^{1^{*}}$, IWONA PARADOWSKA-STANKIEWICZ², LESZEK SZENBORN \\ SABINE SANTIBANEZ ${ }^{4}$, ANNETTE MANKERZ ${ }^{4}$ and BOGUMIŁA LITWIŃSKA ${ }^{1}$
}

\author{
${ }^{1}$ Department of Virology, National Institute of Public Health-National Institute of Hygiene, Warsaw, Poland \\ ${ }^{2}$ Department of Epidemiology, National Institute of Public Health-National Institute of Hygiene, Warsaw, Poland \\ ${ }^{3}$ Department of Pediatric Infectious Diseases Medical University, Wroclaw, Poland \\ ${ }^{4}$ WHO Measles/Rubella European RRL and NRC Measles, Mumps, Rubella Robert Koch-Institut, Berlin, Germany
}

\begin{abstract}
A measles outbreak that affected mainly the Roma ethnic group has been observed in Wrocław, southwest Poland, in spring/summer 2012. There were 15 confirmed measles cases occurring among young Roma people aged from 0 to 16 years including a newborn infant, born by a mother who showed measles symptoms immediately after delivery. Measles virus transmission into the general Polish population was restricted to two contact cases. Initiation of the outbreak by $\mathrm{MeV}$ importation from Romania has been confirmed by detection of $\mathrm{MeV}$ variant "D4-Maramures" circulating in Romania from 2011 to 2012. The outbreak experience highlights once more the still existing problem of immunity gaps in Roma groups moving throughout Europe with a high susceptibility among children and adolescents including young women of child-bearing age.
\end{abstract}

Ke y words: measles outbreak in Poland, MeV variant, $\mathrm{MeV}$ from Romania

Regional or national measles outbreaks involving hard-to-reach population groups, such as the Roma ethnic minority are still a considerable public health problem in several European countries. In recent years, several measles outbreaks probably initiated by measles virus $(\mathrm{MeV})$ importation from large outbreaks in Europe occurred among Roma communities in Poland (Rogalska etal., 2010). The measles outbreak we describe here, was related to the Roma people arriving from Romania.

The programme of vaccination against measles has got a long history in Poland. At the beginning of vaccination in 1975, 1 dose of monovalent measles vaccine was administered and the second dose was introduced in 1991. In 2004, the monovalent vaccine was replaced by the combined measles-mumps-rubella (MMR) vaccine. In 2010, the national vaccine coverage for measles was 98 per cent for three year old children with the first dose, and 97 per cent for 11 year old with the second dose, respectively. The vaccination coverage in highrisk groups or in any sub-populations in Poland is not routinely assessed.

In 2012 in Poland six measles outbreaks were reported in three provinces: 1 in dolnoslaskie, 2 in mazowieckie and 3 in slaskie. Moreover, three imported measles cases were recorded in 2012 (from France,
Ukraine and United Kingdom), which were not linked to any of the observed measles outbreaks (Rogalska et al., 2014). In May 2012, a measles outbreak started in the city of Wrockaw, in the south-west of Poland. It was an another outbreak in the Roma community notified over the last years (Orlikowa et al., 2010). From 17 May (the outbreak notification date) until 1 August 2012 (last case notification date), 17 measles cases were reported to the routine surveillance system in Poland. The number of Roma people living in the community in Wroclaw was estimated at 100 people including 50 children, who arrived in Poland at an unknown time, before the measles outbreak occurred. The epidemiological investigation revealed that some of these children came from Romania.

Out of 17 notified cases, 15 belonged to a Roma community living in a nomad camp in the suburb of the city, among them a 16-year-old young mother who developed measles symptoms (30.05.2012) on the $3^{\text {rd }}$ day after delivery (27.05.2012). The 4-day-old newborn developed mild symptoms (fever), with the absence of rash (31.05.2012). Immunoglobulin therapy was used. There were two contact cases in the general population affecting a medical student working at the infectious diseases unit in the pediatric clinic in Wrocław where measles patients were hospitalized and

\footnotetext{
* Corresponding author: A. Makówka, National Institute of Public Health-National Institute of Hygiene, Departament of Virology; email: amakowka@pzh.gov.pl
} 


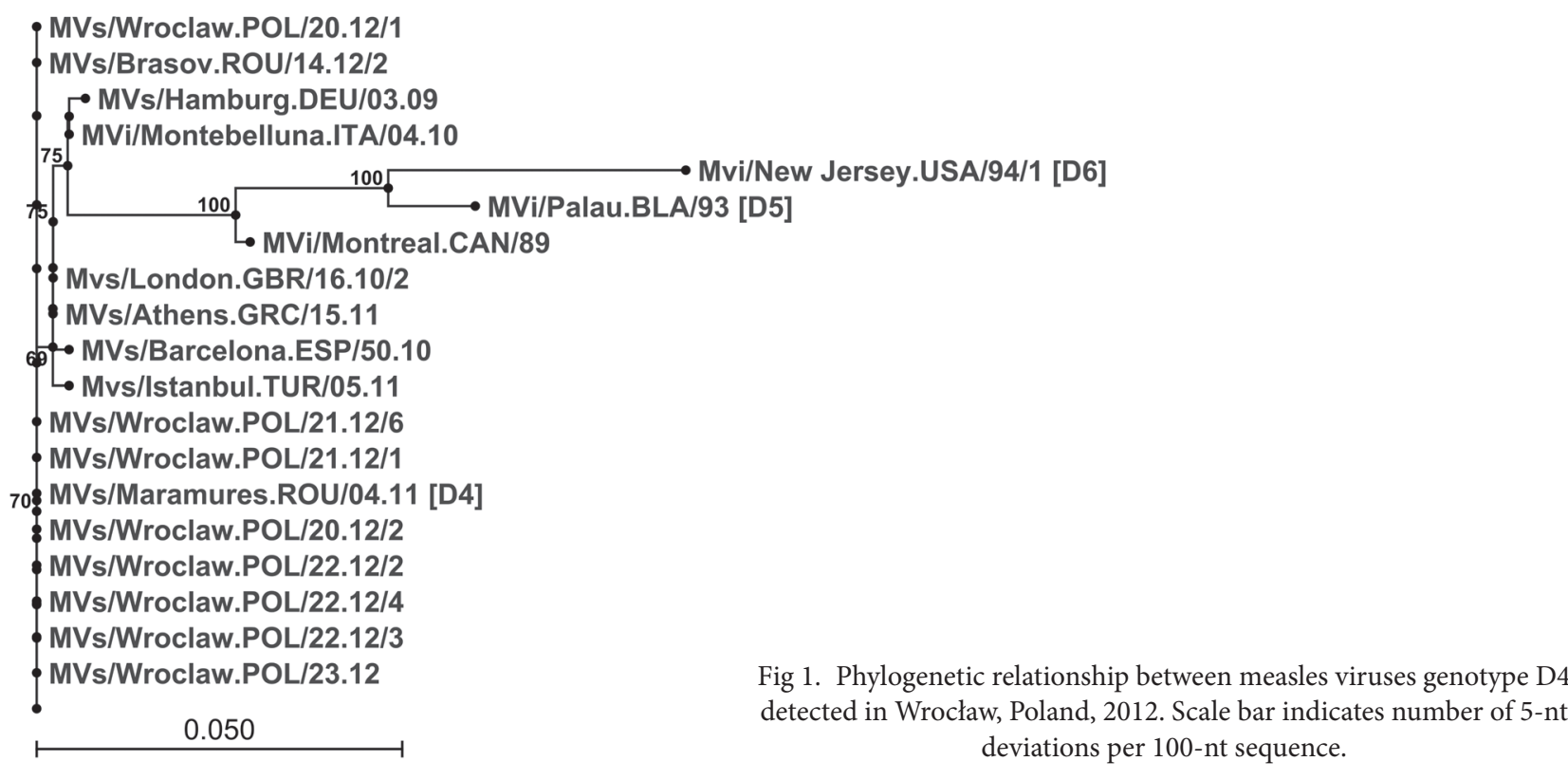

a woman who had been in touch with diseased people of the Roma community. According to the case definition (EU 2008), 12 cases (71 per cent) were classified as a confirmed case and 5 ( 29 per cent) as a probable case. All notified cases were hospitalized in the department of infectious diseases of the Province Wrocław Clinic. One case (a 25 year old woman) developed severe complication as pneumonia.

Data on measles vaccination status of the notified cases show that there were 14 unvaccinated cases and three cases with unknown vaccine status. The local public health authorities decided to implement a vaccination campaign in children belonging to the Roma community living in the city suburbs of Wroclaw.

This study investigates measles outbreak observed among the Roma people with Romanian citizenship, temporarily living in Wrocław, including an intrauterine measles case. A total of 30 samples (9 peripheral blood samples, 12 throat swabs and 9 urine samples) were collected from mid-May to mid-June 2012 from 12 clinically diagnosed measles cases. These cases were reported to WHO Measles Elimination Programme, according to WHO criteria, therefore the bioethical committee approval was not required for collecting samples (WHO, 2012).

Measles virus genome was detected in blood, urine and throat swab samples by nested RT-PCR targeting a highly conserved part of the $\mathrm{MeV}$ nucleoprotein gene (Tischer et al., 2004). Subsequently, for the samples containing $\mathrm{MeV}$ RNA, genotyping was performed according to the WHO recommendation. For this purpose, the variable fragment of the nucleoprotein gene (450 nucleotides encoding the C-terminal part) was sequenced. A sequences were aligned and analyzed by CLC Sequence Viewer 6.5.3 Software. The phyloge- netic tree was constructed by means of the neighborjoining method. Measles virus-containing samples collected from the same patients were sent to the WHO Regional Reference Laboratory for Measles and Rubella (Robert Koch Institute, Berlin) for confirmation the genotyping results.

In the outbreak, 12 suspected measles cases comprising 11 measles cases in the Roma community and 1 contact were confirmed by laboratory investigation. Among these Roma patients there was a newborn infant born to a mother, who fell ill with measles 3 days after the delivery. The results from the nested RT-PCR showed the presence of $\mathrm{MeV}$ genome in 21 clinical samples ( 3 blood samples, 8 urine and 10 throat swabs) collected from 12 patients. The viral RNA was detected in the urine sample collected from the 4-day old child at the fifth day after the occurrence of symptoms. This indicates that there was an intrauterine measles case caused by transplacental infection.

Among the confirmed by RT-PCR measles cases was a medical student, who was infected during her internship in the hospital in Wrocław. The epidemiological investigation had revealed her contact with the Roma children with measles symptoms.

Serological data are not available since the patients of the Roma community refused a blood-test.

The epidemiological and molecular investigations showed that the outbreak in the Roma community in Wroclaw was most probably initiated by a child who had acquired measles in Romania. The $\mathrm{MeV}$ strain detected in 10 outbreak cases (i.e. MVs/Wroclaw.POL/20.12/1[D4], GenBank Accession Number KF939587) belongs to the variant "D4-Maramures" (Named strain: MVs/Maramures.ROU/03.11[D4]) of genotype D4 (Fig. 1). This MV variant had been detected 
in Romania a few weeks before the beginning of the outbreak in Poland (MVs/Brasov.ROU/14.12/2[D4], GenBank Accession No. JX156443) and was not found outside of Romania at this time (MeaNS database, data as of 12 June 2013). The assumption of importation of the outbreak virus from Romania is confirmed by these data.

Vaccination against measles virus was introduced in Poland in 1974/1975. The proportion of vaccinated children is satisfactorily high, more than about 98 per cent. Vaccination resulted in rapid decrease of measles incidence and now Poland is approaching measles elimination. Seventy measles cases were reported in 2012 with incidence 0.18 , while before starting of immunization every year the number of cases was reported in thousands. Nevertheless, occasional measles outbreaks still occur due to the presence of people susceptible to $\mathrm{MeV}$ infection. The recent outbreaks mainly affected the ethnic minority of Roma whereas secondary transmission in the general population was very limited (Rogalska et al., 2010). Genetic characterization of circulating $\mathrm{MeV}$ continuously performed in Poland since 2006 has shown a regionally and temporary very limited spread of various imported $\mathrm{MeV}$ variants (Makówka et al., 2007a ; Makówka and Litwińska, 2008). Measles virus strains isolated from cases in 2006 belonged to genotypes D4 and D5, and that year the same genotypes were found in other European countries. In 2007 $\mathrm{MeVs}$ isolated in Poland were genetically identical with the Ukrainian strain of genotype D6 (Makówka et al., 2007b). During 2008 - 2011 genotype D4, Hamburg strain (MVs/Hamburg.DEU/03.09/), the other cluster than in 2006, was detectable in the number of European countries: Ireland, Austria, Greece, Germany, Turkey, Belgium (Mankerz et al., 2011). The spread of measles virus infection was mainly caused by people from the very mobile Roma ethnic group travelling throughout Europe (Rogalska et al., 2010).

The measles outbreak in Wroclaw in 2012 involved 15 cases of the Roma minority and two cases of the general population. This outbreak was presumably imported from Romania.

The majority of pregnant women had only vaccine immunity and probably never had contact with the wild measles virus. There is no published data on the risk of in utero transmission to the fetus, but measles during pregnancy was associated with high risk of preterm delivery (31\%) (Eberhart-Phillips et al., 1993). When measles break out in a pregnant woman few days before or after delivery, there is a risk of congenital measles related to an incomplete transfer of protective antibodies. The clinical picture is highly variable in the newborn: from asymptomatic form to skin and mucosa rash and pneumonia. There is also a higher risk of developing early subacute sclerosis panencephalitis (Gutierrez et al., 2010). In our case the IVIG were given to newborn after delivery. The newborn had no measles symptoms except mild fever but we detected the excretion of $\mathrm{MeV}$ in urine samples collected on three consecutive days.

There was one case of hospital-acquired infection affecting a medical student who had been in contact with the hospitalized cases of the Roma community. She had probably received only one dose of measles vaccine. There were several measles cases reported recently among health care workers e.g. in Marseilles, France in 2010 or in Italy in 2011. Health care workers are at higher risk of acquiring measles than the general population (Botelho et al., 2011) and nosocomial $\mathrm{MeV}$ transmission by infected medical personnel should be prevented. It is very important that medical personnel including physicians, nurses and medical students as well as social workers are protected against measles by administration of 2 doses of vaccine according to the schedule.

The present study shows that the measles cases among Roma people in Wroclaw in 2012 was another outbreak caused by imported $\mathrm{MeV}$ strains recorded in recent years in Poland. The molecular surveillance together with epidemiological investigation allows to identify sources of $\mathrm{MeV}$ infection and document measles elimination in Poland. This study also underlines the need of supplementary vaccination activities for unimmunized populations.

\section{Acknowledgements \\ Funding for this project was received from the Ministry of Science and Higher Education, Poland (NN 4041139 39).}

\section{Literature}

Botelho-Nevers E., N. Cassir, P. Minodier, R. Laporte, P. Gautret, S. Badiaga, D.J. Thiberville, L. Ninove, R. Charrel and P. Brouqui. 2011. Measles among healthcare workers: a potential for nosocomial outbreak. Euro. Surveill. Jan 13; 16. pii: 19764.

Eberhart-Phillips J.E., P.D. Frederick, R.C. Baron and L. Mascola. 1993. Measles in pregnancy: a descriptive study of 58 cases. Obstet. Gynecol. 82: 797-801.

Gutierrez J., R.S. Issacson and B.S. Koppel. 2010. Subacute sclerosing panencephalitis: an update. Dev. Med. Child. Neurol. 52: 901-907.

Makówka A., W. Gut and B. Litwińska. 2007a. Measles elimination programme on the world and Poland. (in Polish) Przegl. Epidemiol. 61: 135-142.

Makowka A., W. Gut, B. Litwinska, S. Santibanez and A. Mankertz. 2007b. Genotyping of measles and rubella virus strains circulating in Poland in 2007. Euro. Surveill. 12(43).

Makówka A. and B. Litwińska. 2008. Epidemiological surveillance of measles occurrence in Poland in 2006 by means of virological and molecular methods. (in Polish) Przegl. Epidemiol. 62: 539-545. 
Mankertz A., Z. Mihneva, H. Gold, S. Baumgarte, A. Baillot, R. Helble, H. Roggendorf, G. Bosevska, J. Nedeljkovic, A. Makowka and others. 2011. Spread of measles virus D4-Hamburg, Europe, 2008-2011. Emerg. Infect. Dis. 17: 1396-1401.

Orlikova H., J. Rogalska, E. Kazanowska-Zielinska, T. Jankowski, J. Slodzinski, B. Kess and P. Stefanoff. 2010. Spotlight on measles 2010: A measles outbreak in a Roma population in Pulawy, eastern Poland, June to August 2009. Euro. Surveill. Apr 29 15(17). pii: 19550.

Rogalska J., S. Santibanez, A. Mankertz, A. Makowka, L. Szenborn and P. Stefanoff. 2010. Spotlight on measles 2010: An epidemiologi- cal overview of measles outbreaks in Poland in relation to the measles elimination goal. Euro. Surveill. Volume 15, Issue 17, 29 April. Rogalska J., E. Karasek and I. Paradowska-Stankiewicz. 2014. Measles in Poland in 2012. (in Polish). Przegl. Epidemiol. 68(2): 187-90.

Tischer A. S. Santibanez, A. Siedler, A. Heider and H. Hengel. 2004. Laboratory investigations are indispensable to monitor the progress of measles elimination-results of the German Measles Sentinel 1999-2003. J. Clin. Virol. 31: 165-178.

WHO. 2012. Library Cataloguing-in-Publication Data. Global measles and rubella strategic plan: 2012-2020. 